\title{
Growth and real time corrosion resistance monitoring of lead decanoate coatings
}

\author{
Annemie Adriaens ${ }^{a, *}$, Frank De Bisschop ${ }^{b}$, Mark Dowsett ${ }^{c}$, Bart Schotte ${ }^{a}$ \\ a Department of Analytical Chemistry, Ghent University, Krijgslaan 281-S12, B-9000 Ghent, Belgium \\ ${ }^{\mathrm{b}}$ Physics Laboratory, Faculty of Medicine, Ghent University, Krijgslaan 281-S12, B-9000 Ghent, Belgium \\ ${ }^{\mathrm{c}}$ Department of Physics, University of Warwick, Coventry CV4 7AL, UK
}

\section{A R T I C L E I N F O}

\section{Article history:}

Received 18 February 2008

Received in revised form 23 April 2008

Accepted 26 May 2008

Available online 7 July 2008

\section{PACS:}

81.65.Kn

68.47.De

Keywords:

Lead

Corrosion

Coatings

Growth mechanism

\begin{abstract}
A B S T R A C T
Lead is very susceptible to corrosion in the presence of organic acids and humidity. A potential countermeasure is to apply a lead carboxylate coating by immersing the metal in a sodium carboxylate solution/suspension. In this work we report on the degree of surface coverage and the corrosion resistance of a lead decanoate $\mathrm{Pb}\left(\mathrm{C}_{10}\right)_{2}$ coating as a function of treatment time. Results show that the surface coverage reaches $91 \%$ after $15 \mathrm{~min}$ and about $100 \%$ after $1 \mathrm{~h}$ in a $0.05 \mathrm{M}$ sodium decanoate solution. The corrosion resistance, as indicated by electrochemical impedance spectroscopy, continues to increase even after $6 \mathrm{~h}$ of immersion. In addition, we show that in the case of planar transport, a diffusion layer of $17 \mathrm{~mm}$ thickness exists, wherein the sodium decanoate concentration drops linearly from its bulk value to almost zero at the solid/surface interface.
\end{abstract}

(c) 2008 Elsevier B.V. All rights reserved.

\section{Introduction}

Lead objects exposed to the atmosphere or buried usually corrode only slightly as the formation of a protective film, mainly of lead carbonates, drastically inhibits corrosion [1]. This explains why lead objects found at archaeological sites are very often in good condition. Conversely, lead corrodes severely in humid environments, specifically in the presence of organic acids [2]. This accelerated degradation, commonly referred to as active corrosion, takes place, e.g. in display cases of museums and on organ pipes in churches or concert halls $[2,3]$. The objects readily lose mechanical stability and surface details and may be lost entirely.

A countermeasure has been found in the use of coatings deposited from solutions of saturated linear monocarboxylates of the type $\mathrm{CH}_{3}\left(\mathrm{CH}_{2}\right)_{n-2} \mathrm{COONa}(n=7-11)$, hereafter called $\mathrm{NaC}_{n}$. In an initial study, Rocca and Steinmetz [4] showed that the protection is due to the growth of a crystalline lead monocarboxylate layer $\left(\mathrm{CH}_{3}\left(\mathrm{CH}_{2}\right)_{n-2} \mathrm{COO}\right)_{2} \mathrm{~Pb}(n=7-11)$, hereafter called $\left.\mathrm{Pb}\left(\mathrm{C}_{n}\right)_{2}\right)$, which passivates lead surfaces and inhibits corrosion. The degree of inhibition depends on the carbon chain length and on the carboxylate concentration-higher chain lengths and higher

\footnotetext{
* Corresponding author. Tel.: +32 9264 4826; fax: +32 92644960.

E-mail address: annemie.adriaens@ugent.be (A. Adriaens).
}

concentrations commonly result in higher effectiveness [4]. However, the solubility of sodium monocarboxylates drastically decreases with increasing chain length. A compromise between treatment cost, carbon chain length and water solubility lies in the application of $\mathrm{Pb}\left(\mathrm{C}_{10}\right)_{2}$ (lead decanoate) prepared from a $0.05 \mathrm{M}$ $\mathrm{NaC}_{10}$ solution [5].

The present work focuses in more depth on the $\mathrm{Pb}\left(\mathrm{C}_{10}\right)_{2}$ coatings and discusses in the first instance the surface coverage of the coating as a function of treatment time. The latter was assessed on the basis of solid/liquid contact angle measurements, at regular time intervals. Electrochemical impedance spectroscopy (EIS) measurements were performed in parallel, to study the corrosion resistance of the coating as a function of treatment time. In addition, the effects of layer thickness of the sodium decanoate solution were studied by characterizing the mass gain as a function of treatment time, with the aim of optimizing the deposition.

\section{Experimental}

\subsection{Preparation of solution}

The preparation of the $0.05 \mathrm{M}$ sodium decanoate solution was done by finely dispersing $4.3068 \mathrm{~g}$ of decanoic acid (Fluka, Belgium, 98\%) in $50 \mathrm{~mL}$ of water and by subsequently neutralizing the suspension with a $0.1 \mathrm{M} \mathrm{NaOH}$ solution, until 
$\mathrm{pH}$ 7. The initial turbidity of the suspension at this point disappeared. The solution was then adjusted to a volume of $500 \mathrm{~mL}$, using deionized water. It should be noted at this stage that the solubility of decanoic acid in water is extremely low $\left(0.015 \mathrm{~g} / 100 \mathrm{~g}\right.$ at $\left.20^{\circ} \mathrm{C}\right)$ [6], which leads to the formation of a highly dilute suspension.

\subsection{Samples and deposition of the coating}

We examined two types of lead samples: electrodes and plates. The electrodes used for the EIS experiments and for assessment of the surface coverage were made out of a circular lead rod, $12 \mathrm{~mm}$ in diameter (Goodfellow, purity 99.95\%). The coupons were connected to a brass rod by means of conducting glue and encapsulated in epoxy resin, so that only one surface was exposed to the electrolyte. A brass stud in a tapped hole in the rod attaches the electrode to the cell and an O-ring seals against the epoxy to exclude electrolyte from the electrical contact thus formed. The lead plates (dimension $20 \mathrm{~mm} \times 20 \mathrm{~mm} \times 1 \mathrm{~mm}$, Goodfellow, purity 99.95\%) were used for the desorption rate measurements, the mass gain experiments and the determination of the layer thickness of the decanoate solution that gives rise to the most efficient deposition. Both types of samples were ground on 1200 grit SiC paper to obtain a fresh surface. Further smoothing of the surface was carried out using a soft, abrasive-free tissue. In order to deposit the coating, both types of samples were immersed in $50 \mathrm{~mL}$ of the above-mentioned decanoate solution.

\subsection{Assessment of the surface coverage}

The surface coverage was determined by measuring the contact angle of sessile droplets positioned on decanoate-coated surfaces (immersion of freshly polished electrodes in the sodium decanoate solution, for different time intervals between 0 and $180 \mathrm{~min})$. Contact angle determinations were based on a thermodynamic/mathematical model for calculating the profile of sessile drops [7]. The method uses readily accessible parameters such as the height and base radius of the drop (Fig. 1), the drop volume as well as the density of the liquid and its surface tension, for a mathematical reconstruction of the drop profile, including the calculation of the solid/liquid contact angle. A Zeiss projection microscope [8] and a calliper were used

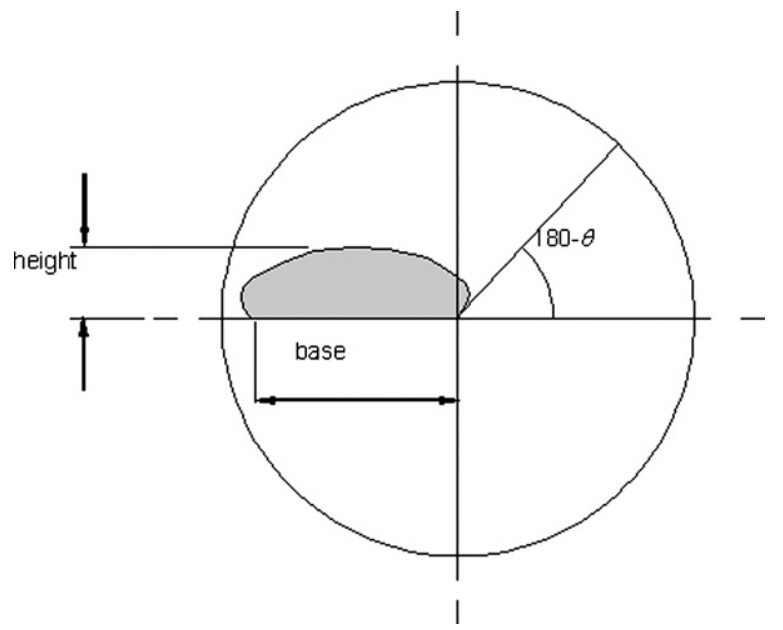

Fig. 1. Projected image of a sessile droplet for the determination of its geometrical parameters. to measure the height and the ground plane radii of $50 \mu \mathrm{L}$ sessile droplets, to an accuracy of $0.001 \mathrm{~mm}$.

\subsection{Desorption rate and critical micelle concentration}

The selection of an appropriate test liquid for the contact angle measurements appeared rather difficult; the surface tension of water, serving as a test liquid, might be affected by the release of $\mathrm{Pb}\left(\mathrm{C}_{10}\right)_{2}$, thereby changing the magnitude of the contact angle. We therefore studied the possible effects of $\mathrm{Pb}\left(\mathrm{C}_{10}\right)_{2}$ desorption, prior to the contact angle measurements, using a Wilhelmy setup for surface tension measurements [9]. In this experiment a decanoatecoated lead platelet (coating time $15 \mathrm{~min}$ ) was suspended from an electro-balance to ensure reproducible positioning and to avoid any effects of buoyancy. The traction force, $F_{\text {platelet, }}$ in such circumstances, is given by

$F_{\text {platelet }}=p \gamma_{\mathrm{LV}} \cos \theta$

where $\gamma_{\mathrm{LV}}$ is the surface tension, $p$ is the length of the platelet perimeter and $\theta$ is the magnitude of the contact angle. Any release of $\mathrm{Pb}\left(\mathrm{C}_{10}\right)_{2}$ was expected to affect the traction force on the balance, thereby providing information of the desorption rate. Should it occur, desorption could presumably be countered by using droplets with a sodium decanoate concentration well above the critical micelle concentration ( $\mathrm{cmc}$ ). The surface tension, in these circumstances, would be almost constant and independent of the effects of desorption. However, the cmc of sodium decanoate, unknown at the start of the experiment, needed to be determined. With that objective, a set of solutions was prepared which contained concentrations up to $0.02 \mathrm{M}$ sodium decanoate (Fluka, $98 \%$ ). The surface tension and conductivity of these were determined after 4 days of stabilization, in order to extract the cmc. Surface tension measurements were determined in a similar way to the desorption effects (the Wilhelmy method), i.e. by measuring the traction force exerted on a platinum platelet. The wetting of the platelet was perfect for all of these measurements, i.e. $\theta=0^{\circ}$. Conductivities were measured using a type CDC 641T sensor (Radiometer, Denmark), with a CDM 210 controller from the same manufacturer.

\subsection{Electrochemical impedance spectroscopy of the lead decanoate coating}

EIS provides a measure of coating quality (freedom from pinholes, resistance to moisture penetration, etc.), with one of the quality indicators being the (ohmic) resistance of the layer. Measurements were made in situ during coating growth using an Autolab PGSTAT20 potentiostat with FRA software (Ecochemie B.V., The Netherlands). The frequency was scanned from $1 \mathrm{kHz}$ to $100 \mathrm{mHz}$ over a period of $10 \mathrm{~min}$. The signal amplitude was $0.1 \mathrm{~V}$. In the range $1 \mathrm{kHz}-1 \mathrm{~Hz}$, a logarithmic spread of frequencies was used over 50 points. In the range $1 \mathrm{~Hz}-100 \mathrm{mHz}$, the frequencies were logarithmically distributed over 10 points. The magnitude of the imaginary part of the complex impedance was plotted as a function of the real part (Nyquist plot).

\subsection{Impact of diffusion of the sodium decanoate on the coating process}

The impact of diffusion of the sodium decanoate was studied using mass gain measurements (Mettler AE240), which allowed us to determine that layer thickness of decanoate solution which gave rise to the most efficient deposition. The setup consisted of a PVC receptacle, subdivided into compartments filled with the decan- 
oate solution. The width of each compartment was adjusted to yield surrounding liquid layers of $4.5,8.5,12.5$ and $50 \mathrm{~mm}$ thickness on either side of the lead plates immersed in the respective compartments.

\section{Results and discussion}

\subsection{Critical micelle concentration}

A decanoate solution with concentration well above the $\mathrm{cmc}$, initially, was presumed to be most appropriate as test liquid for contact angle measurements (ut supra). Surface tension and conductivity were therefore measured as a function of the $\mathrm{NaC}_{10}$ concentration in order to determine the $\mathrm{cmc}$, if any. The results are shown in Fig. 2. The drop of surface tension with increasing decanoate concentration appears to be quite characteristic to many surfactants [10]. However, the bend at about $3.6 \mathrm{mM}$ actually marks the saturation of interfacial adsorption, rather than any cmc. A pronounced minimum, symptomatic of the $\mathrm{cmc}$ and the micelle formation within the present range of concentrations remains absent. This is confirmed by decanoate conductivity and diffusivity data in the literature [11]. It should be noticed that the decanoate concentrations in Fig. 2 are analytical ones, as we are dealing with a tensio-active species, the real concentration in the bulk liquid could be substantially lower due to interfacial adsorption and remains inaccessible. Conductivity measurements, nonetheless, show a steady increase as of $3.6 \mathrm{mM}$, indicating that the bulk concentration keeps on increasing with the analytical one. The conductivity, furthermore, shows a distinct discontinuity at about $1.5 \mathrm{mM}$, indicating a limitation of the free decanoate concentration in the bulk, while interfacial adsorption still is in the process of saturation.

The decanoate concentration of test liquids for contact angle measurement, in our initial measurements for such reasons was well above that $3.6 \mathrm{mM}$ concentration. Unfortunately, these test liquids of low surface tension caused enhanced spreading, seriously deteriorating the symmetry and stability of sessile drops on decanoate treated substrates. The use of decanoate solutions as test liquids, for such reasons, was abandoned.

\subsection{Desorption rate and assessment of surface coverage}

Our initial contact angle measurements on decanoate coated substrates, using deionized water for the sessile drops, showed some interference from decanoate desorption. The latter, lowering the substrate's surface coverage and the surface tension of sessile

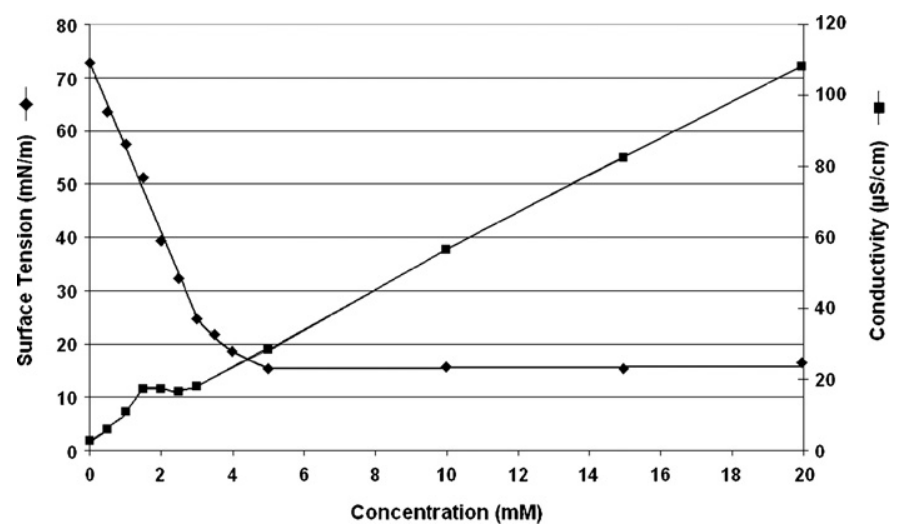

Fig. 2. Surface tension (diamonds) and conductivity (squares) as a function of the $\mathrm{NaC}_{10}$ concentration.

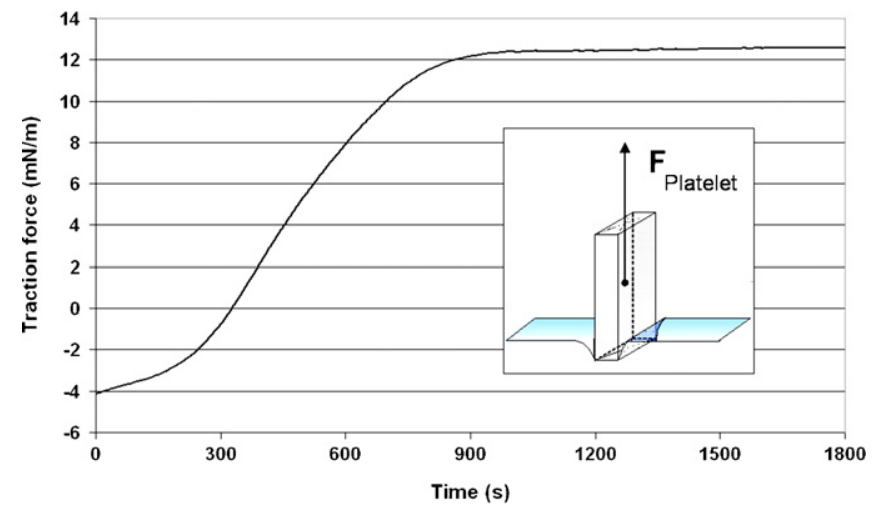

Fig. 3. Traction force on a decanoate-treated lead platelet as a function of time with pure water serving as a test liquid. Inset: initial configuration with $\theta=113.9^{\circ}$, progressively decreasing.

drops, decreases the contact angle. The effect was visualised by monitoring the traction force on a decanoate-coated lead platelet (Fig. 3), with pure water serving as a test liquid. The lower side of the platelet was slightly submerged (cf. inset) which causes the initial traction to be negative. As the data shows, the decrease of the contact angle actually dominates the increase of traction, any lowering of surface tension due to released decanoate having an opposite effect.

However, as Fig. 3 also shows, the decanoate desorption and its complicating effects remain negligible during the first tens of seconds. This delay actually allows us to determine contact angle magnitudes to a sufficient degree of accuracy, with water serving as the test liquid; repeated tests prove that the error remains below $1^{\circ}$ during the first $5 \mathrm{~min}$. The fractional surface coverage $(\varepsilon)$ as a function of treatment time could therefore be calculated on the basis of the following equation [12]:

$\varepsilon=\frac{\cos \theta^{*}-\cos \theta_{2}}{\cos \theta_{1}-\cos \theta_{2}}$

where $\theta_{1}$ and $\theta_{2}$ represent the contact angles on the constituting (pure) surfaces (lead and sodium decanoate, respectively) and $\theta^{*}$ is the contact angle on the composed surface (i.e. the decanoate coated lead surface). The initial contact angle $88.8^{\circ}$ measured on bare lead was found to increase to about $113.9^{\circ}$ after $1 \mathrm{~h}$, with the most rapid increase taking place during the first $15 \mathrm{~min}$. A similar profile was obtained for the fractional surface coverage (Fig. 4). Starting with a bare lead substrate, the coverage reached $91 \%$ after $15 \mathrm{~min}$ and about $100 \%$ after $1 \mathrm{~h}$.

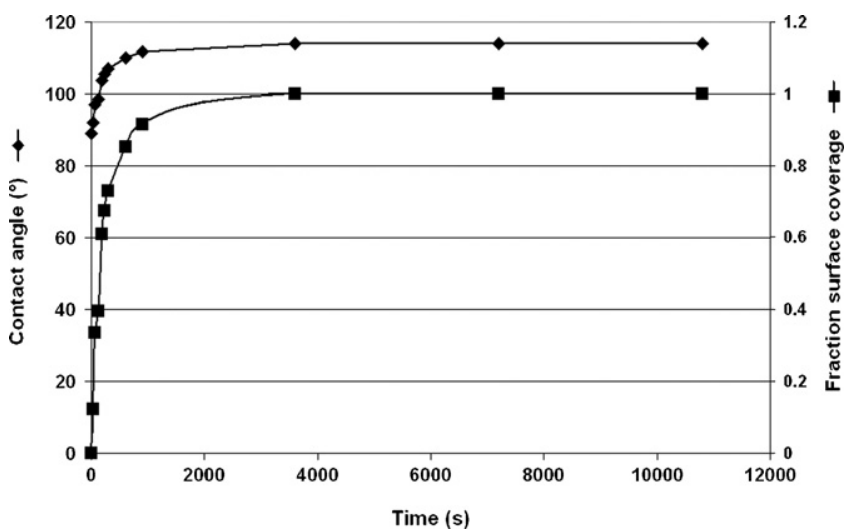

Fig. 4. Contact angle (diamonds) and fractional surface coverage (squares) as a function of treatment time. 


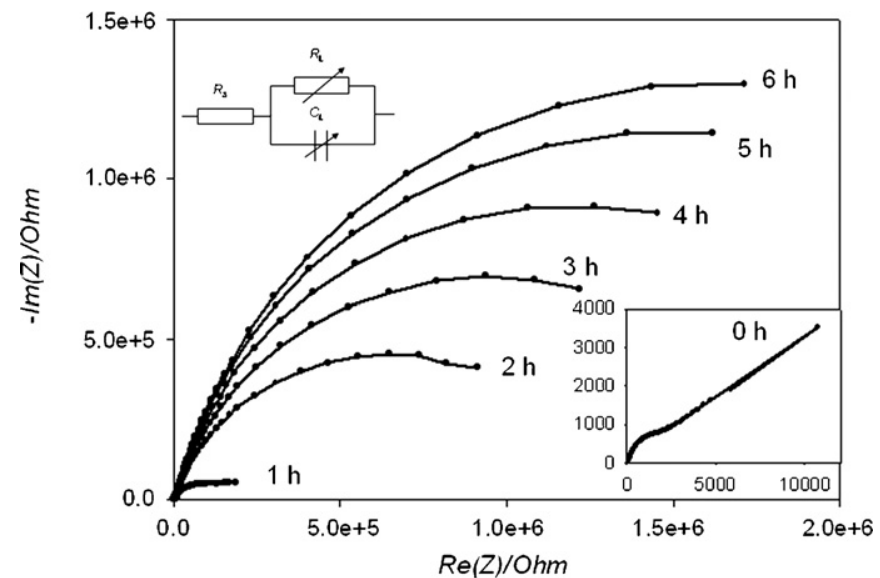

Fig. 5. Nyquist plots of EIS data as a function of immersion time (values at the start of each curve). Upper inset: equivalent Randles circuit. Lower inset: data for bare lead. The frequency was scanned from $1 \mathrm{kHz}$ to $100 \mathrm{mHz}$ over period of $10 \mathrm{~min}$. The signal amplitude was $0.1 \mathrm{~V}$. In the range $1 \mathrm{kHz}-1 \mathrm{~Hz}$, a logarithmic spread of frequencies was used over 50 points. In the range $1 \mathrm{~Hz}-100 \mathrm{mHz}$, the frequencies were logarithmically distributed over 10 points.

\subsection{Electrochemical impedance spectroscopy of the lead decanoate coating}

Fig. 5 shows the Nyquist plots with the coating time at the start of each curve as a parameter. Note that time runs from left to right (frequency scanned from high to low). A Randles circuit was taken as equivalent to the cell (upper inset to Fig. 5), with a Nyquist plot in the form of a semicircle [13]. The electrolyte resistance is represented by $R_{\mathrm{s}}$, but the layer capacitance $C_{1}$ and coating resistance $R_{1}$ are shown as variable because there will have been significant layer growth during the acquisition of each curve, resulting in some distortion. Thus, although the data apparently consist of "depressed" approximate semicircles (with centres slightly below the real axis), the possibility of constant phase elements [13] other than the capacitance and the resistance was ignored. Likewise, a more complicated model (e.g. two capacitative circuits as often used for coated metals) was not used because the effects of time dependence cannot be distinguished from those of coalesced twin semicircles, so any parameters extracted would be ambiguous. Nevertheless, the data show a steady increase in $R_{1}$ into the mega-ohm range with growth time, indicating increased thickness and coverage.

The data for $0 \mathrm{~h}$ (lower inset to Fig. 5) are consistent with the initial presence of a layer possibly native oxide followed by rapid take-off of growth to the right of the plot. (Time-resolved XRD measurements indicate the growth of both lead oxide $(\mathrm{PbO})$ and decanoate at this early stage [14].)

\subsection{Impact of diffusion of the sodium decanoate on the coating process}

The adherence of decanoate to lead substrates and its selfadherence as well, give rise to strong multi-layer coatings. The process is fast and essentially irreversible. As time records show the mass growth, very rapid initially, within minutes takes on an almost constant value (Fig. 6). The latter depends on the layer thickness of the decanoate solution that surrounds the sample upon treatment. The process, presumably, can be understood on grounds of the model represented in Fig. 7, which illustrates progressive depletion in the close vicinity of the solid/liquid interface and its effect on the adsorption rate.

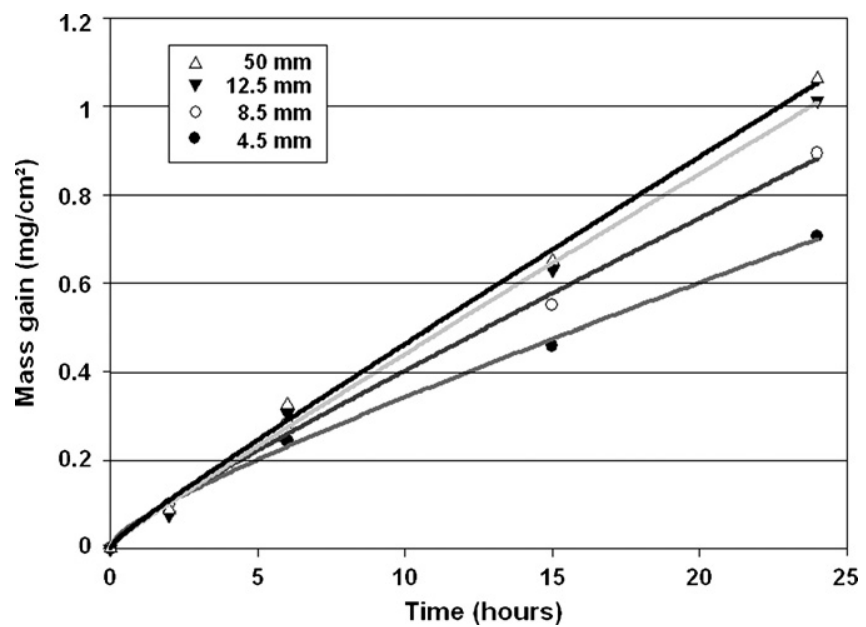

Fig. 6. Mass gain as a function of time for varying thickness of the decanoate solution layer that surrounds the lead substrate.

The mass gain rate $(\mathrm{d} m / \mathrm{d} t)$, in the present case of planar diffusion and presumably of quantitative adherence, is expected to respond to Fick's diffusion law:

$\frac{\mathrm{d} m}{\mathrm{~d} t}=J(x)=-D \frac{\partial C}{\partial x}$

where $J(x)$ represents the flux density perpendicular to the interface, $D$ the decanoate diffusivity and $C(x)$ its concentration. As Fig. 6 shows, the mass gain rate at $50 \mathrm{~mm}$ layer thickness takes on an almost constant value already at about $1 \mathrm{~min}$ after immersion. The final slope of the concentration profile $C(x)$ and its intersection with the horizontal at $C_{\mathrm{b}}$ (bulk concentration) implicate the existence of a diffusion layer of definite thickness $\delta$. Furthermore, that slope, owing to the presumption that $C_{0}$ is extremely low, may be approximated for time is infinite as

$\left(\frac{\partial C}{\partial x}\right)_{t=\infty} \cong \frac{C_{\mathrm{b}}}{\delta}$

so that Eq. (3) can be rewritten as

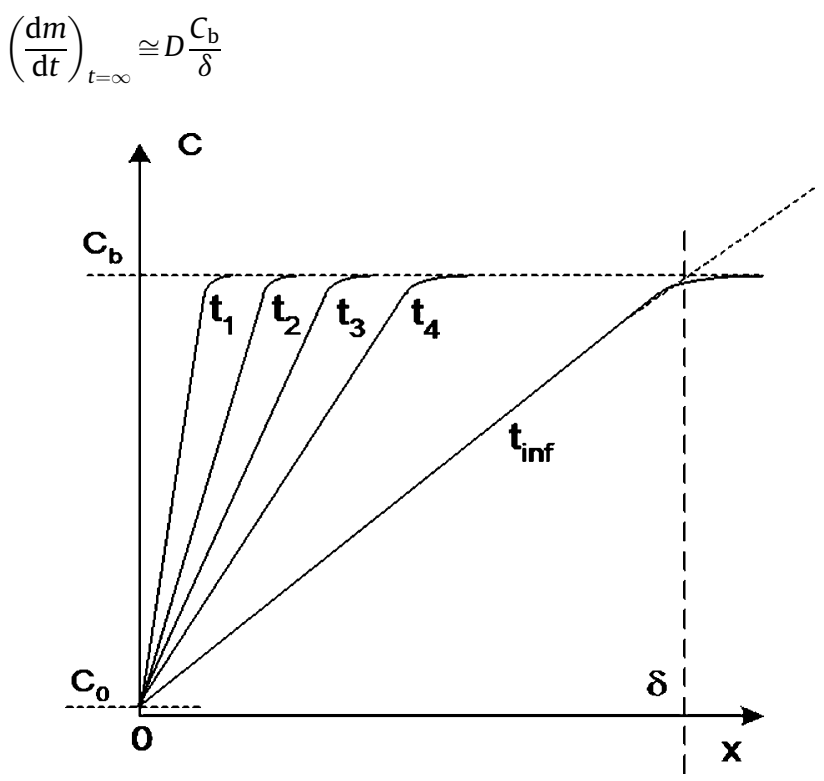

Fig. 7. Scheme of sodium decaonate depletion at the solid/liquid interface. $\delta=$ thickness of the depletion layer; $C_{\mathrm{b}}=$ bulk concentration; $C_{0}=$ concentration at the solid/liquid interface. 
Eq. (5) allows us to determine the thickness $\delta$ of that diffusion layer. It should be noticed, in this context, that the diffusivity of sodium decanoate is highly concentration dependent. For the present concentration of $0.05 \mathrm{M}$, the value of $2.1 \mathrm{~m}^{2} \mathrm{~s}^{-1}$ is mentioned in the literature [11]. Insertion of this and of the remaining parameters in Eq. (5) produces a numerical value of $17.6 \mathrm{~mm}$ for the thickness, $\delta$, of the diffusion layer. Any thickness of below that value, so as Fig. 6 confirms, must be expected to cause disturbance of the concentration profile, giving rise to a nonuniform and/or retarded coating.

\section{Conclusions}

In this work, we have investigated the deposition of lead decanoate coatings produced by immersion of a lead substrate in a $0.05 \mathrm{M}$ sodium decanoate solution.

Solid/liquid contact angle measurements, using water as the test liquid, allowed the determination of the fractional surface coverage of lead substrates coated with $\mathrm{Pb}\left(\mathrm{C}_{10}\right)_{2}$ as a function of treatment time. Perturbing effects of decanoate desorption were shown to remain negligible, provided the measurements are done within a reasonably short time. Starting with a bare lead substrate, the initial contact angle of $88.8^{\circ}$ was found to increase to about $113.9^{\circ}$ after $1 \mathrm{~h}$, the most rapid change taking place during the first $15 \mathrm{~min}$. The surface coverage proceeds at a similar rate; it reaches $91 \%$ after $15 \mathrm{~min}$ and about $100 \%$ after $1 \mathrm{~h}$.

Parallel electrochemical impedance measurements demonstrated a continuous increase of the corrosion resistance as a function treatment time, indicating multi-layer adsorption and a highly effective self-adherence of the deposited sodium decanoate. In addition mass growth rate measurements showed an impact of the layer thickness of the decanoate solution in contact with the substrate during treatment. As the adsorption model confirms, the deposition rate from $0.05 \mathrm{M}$ decanoate solutions in conditions of planar diffusion is governed by the concentration gradient within a layer of about $17 \mathrm{~mm}$ thickness. The deposition rate in such conditions and at any higher layer thickness, is diffusion limited. Conversely, any layer thickness below $17 \mathrm{~mm}$ decreases the mass gain rate, because of (additional) depletion in the vicinity of the solid/liquid interface.

\section{Acknowledgement}

The present work was supported by the Research Foundation Flanders (Belgium).

\section{References}

[1] T. Graedel, J. Electrochem. Soc. 141 (4) (1994) 922-927.

[2] J. Tétréault, J. Sirois, E. Stamatopoulou, Stud. Conserv. 43 (1998) 17-32.

[3] T. Clarke, Nature 427 (2004) 8-9.

[4] E. Rocca, J. Steinmetz, Corros. Sci. 43 (2001) 891-902.

[5] E. Rocca, C. Rapin, F. Mirambet, Corros. Sci. 46 (2004) 653-665.

[6] S. Budavari, M.J. O’Neil, A. Smith, P.E. Heckelman, J.F. Kinneary, The Merck Index, twelfth edition, Merck Research Laboratories, New Jersey, 1996.

[7] M. Bracke, F. De Bisschop, P. Joos, Prog. Colloid Polym. Sci. 76 (1988) 251-259.

[8] F. De Bisschop, W. Rigole, J. Colloid Interf. Sci. 88 (1982) 117-128.

[9] G.T. Barnes, I.R. Gentle, Interfacial Science: An Introduction, Oxford University Press Inc., New York, 2005.

[10] W.A. Zisman, in: R.F. Gould (Ed.), Contact Angle, Wettability, and Adhesion, American Chemical Society, Washington, 1964, pp. 1-51.

[11] Z. Deng, H. Lu, G.G. Leaist, J. Chem. Eng. Data 41 (1996) 214-217.

[12] L.O. Brockway, JonesF R.L., in: R.F. Gould (Ed.), Contact Angle, Wettability, and Adhesion, American Chemical Society, Washington, 1964, pp. 275-294.

[13] A. Amirudin, D. Thierry, Prog. Org. Coat. 26 (1995) 1-28.

[14] M.G. Dowsett, A. Adriaens, B. Schotte, G.K.C. Jones, L. Bouchenoire, in: C. Degrigny, R. van Langh, I. Joosten, B. Ankersmit (Eds.), Metal 07, vol. 3, Rijksmuseum Amsterdam, Amsterdam, 2007, pp. 26-31. 